\title{
Notas sobre a fala masculina e feminina entre os Apyãwa-Tapirapé
}

\author{
Male and female speech among the Apyãwa-Tapirapé \\ Koxamaxowoo Tapirapé ${ }^{1}$ \\ Mônica Cidele $\mathrm{Cruz}^{2}$
}

DOI 10.26512/rbla.v11i02.28507

Recebido em setembro/2019 e aceito em outubro/2019.

Resumo:

$\mathrm{O}$ artigo aborda a distinção entre a fala masculina e feminina entre os Apyãwa, também, conhecidos como Tapirapé. São destacados como traços fortes dessa distinção termos de parentesco e partículas, estas não descritas em termos de suas respectivas semânticas, até então, pelos trabalhos descritivos existentes sobre a língua. A pesquisa foi motivada pela preocupação da neutralização em curso da distinção de importância fundamental para identidade do povo Apyãwa, em detrimento das marcas próprias da fala feminina. A pesquisa, realizada em língua tapirapé e coordenada por uma falante Apyãwa, ressalta a importância do protagonismo indígena na pesquisa linguística e no fortalecimento de sua língua nativa.

Palavras-chave: Língua Apyãwa. Distinção entre fala masculina e feminina. Termos de parenteco. Partículas. Identidade linguística.

\begin{abstract}
:
The article addresses the distinction between male and female speech among the Apyãwa, also known as Tapirapé. Strong features of this distinction are kin terms and particles, the latter not described in terms of semantic features until then by descriptive works on the language. The research was motivated by the concern of the ongoing neutralization of a distinction of fundamental importance for the identity of the Apyãwa people, to the detriment of the female speech markers. The research, conducted in the tapirapé language and coordinated by an Apyãwa speaker, underscores the importance of indigenous leadership in linguistic research and in the strengthening of her native language.
\end{abstract}

Keywords: Apyãwa Language. Male and female speech distinctions. Kin terms. Particles. Linguistic identity.

1 Graduada em Licenciatura Intercultural Indígena, com habilitação em Línguas, Artes e Literatura pela Faculdade Indígena Intercultural-Faindi/Unemat.

2 Doutora em Linguística pela Unicamp, Coordenadora do projeto de pesquisa: Fonologia das línguas nambikwara: subgrupos Mamaindê, Negarotê, Kithaulu, Wakalitesu, Alantesu, Hahaintesu e Wasusu (CNPQ). E-mail: monicacruz@unemat.br 


\section{Introdução}

Neste artigo, tratamos de expressões da fala masculina e feminina que distinguem o gênero biológico do falante na língua apyãwa (Tapirapé). A pesquisa, cujos resultados são aqui apresentados, foi realizada na aldeia Tapi 'itãwa, localizada na Terra Indígena Urubu Branco, município de ConfresaMT. Contribuíram para a pesquisa, realizada por meio de entrevistas na língua apyãwa, Korirã Jorge Tapirapé (70 anos de idade) e Taparawoo Tapirapé (68 anos de idade, anciãos que se preocupam com a vitalidade da língua e da cultura do seu povo.

A língua apyãwa foi classificada como pertencente ao sub-ramo IV da família linguística Tupi-guarani (tronco Tupi) por Rodrigues (1984-1985), juntamente com o Asuriní do Tocantins, o Parakaná, o Suruí Aikewára, o AváCanoeiro, o Tembé e o Guajajára.

Os Apyãwa vivem em duas terras indígenas: Terra Indígena Urubu Branco, localizada nos municípios de Confresa e Porto Alegre do Norte-MT, cujas aldeias são Tapi'itãwa, Myryxitãwa e Tapiparanytãwa, e na Área Indígena Tapirapé/Karajá que está localizada no município de Santa Terezinha-MT, onde há a aldeia Akara'ytãwa.

A pesquisa considerou a preocupação dos mais velhos com o fato de que muitas jovens mulheres não estão fazendo uso das marcas da fala feminina, substituindo-as pelas marcas características da fala dos homens, um fato que vem se agravando e ameaçando a perda total de uma importante distinção cultural expressa pela língua apyãwa. Trata-se de uma mudança induzida pelo contato com o Português e outras línguas, e não uma mudança natural, interna à língua, haja vista, a velocidade com que evolui.

O presente registro, tem, portanto, um objetivo prático: alertar a comunidade e professores Apyãwa quanto à situação de perda de um dos traços fundamentais da cultura apyãwa, que é a distinção entre a fala das mulheres e a fala dos homens.

\subsection{Sobre o povo Apyãwa (Tapirapé)}

A Terra Indígena Urubu Branco, onde vive a maioria dos Apyãwa, dista 28 $\mathrm{km}$ da cidade de Confresa-MT. É a terra tradicional do povo Apyãwa, chamada pelos antepassados de Ipirakwaritãwa "lugar sagrado", atualmente denominado Tapi'itãwa (Terra Indígena Urubu Branco). Nesse lugar tradicional existiam várias aldeias Apyãwa, dentre as quais, Maakotãwa, Moo'ytãwa, Xexotãwa e Tokynookwatãwa. Com a chegada de não indígenas a Apyãwa, vieram com eles doenças estranhas ao povo - sarampo, catapora, malária, gripe entre outras -, às quais o povo Apyãwa não resistia, o que quase o levou à extinção. ${ }^{3}$ Os

$3 \mathrm{Na}$ década de 50, os Apyãwa foram levados pelo SPI (Serviço de Proteção ao Índio) para 
sobreviventes foram obrigados a procurar atendimento de saúde na Terra Indígena Tapirapé-Karajá, oportunizando a invasão de fazendeiros na terra Urubu Branco. Mas os velhos Apyãwa nunca esqueceram sua terra imemorial, terra muito boa para o cultivo de suas plantas e onde há os conhecidos flechais dos Apyãwa.

Em 1993, os Apyãwa retomaram a sua Terra original, conseguindo a sua demarcação, garantindo 178. 000 hectares dela. Fundaram, assim, a aldeia Tapi'itãwa, onde vive a maior parte do povo Apyãwa. A aldeia tem a forma tradicional circular, sendo que a escola fica fora do círculo. Todos os funcionários da escola são Apyãwa.

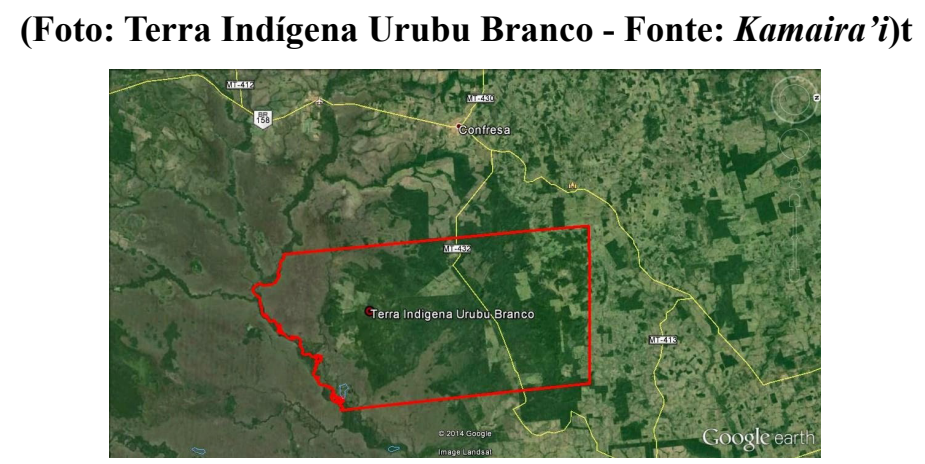

\section{Perdas linguísticas na língua Apyãwa induzidas por contato}

O povo Apyãwa mantém sua língua e cultura original, valorizando a cada dia suas práticas culturais tradicionais, embora as influências externas sejam uma constante ameaça. Preocupados com a adoção massiva de palavras do português adotadas ao longo do contato com os não índios, os professores resolveram pesquisar sobre esse tema, junto com os alunos do ensino fundamental e criar expressões próprias da língua apyãwa para nomear os empréstimos culturais do mundo ocidental. Motivadas por essa iniciativa, tivemos a oportunidade de consultar dois anciões Apyãwa: Korirã Jorge Tapirapé e Taparawoo Tapirapé, moradores da aldeia Towajaatãwa sobre a distinção entre as falas masculina e feminina, que vêm sofrendo neutralização, em detrimento da fala feminina. Ressaltamos que tanto a fala dos homens quanto a fala das mulheres são significativas para o povo Apyãwa/Tapirapé. São parte da cultura e identidade étnica Apyãwa, por isso, é importante que seja valorizada e preservada pelas futuras gerações.

\section{As marcas da fala masculina e feminina dos Apyãwa}

Há expressões linguísticas distintivas das falas masculina e feminina

aldeia Itxalá, do povo Karajá, onde receberam atendimento das Missões Católicas. 
que são usadas nos enunciados cotidianos, como são os casos dos termos de parentesco referenciais e vocativos. Outras expressões, verbos, interjeições e partículas discursivas são usadas entre pessoas do mesmo sexo, como entre homens quando se reúnem no terreiro da Takãra (Casa dos homens), quando praticam atividades conjuntas, como pesca, caça e elaboração de artefatos. As marcas da fala feminina são correntes nas interações entre elas, assim como são correntes as marcas de ambas as falas quando há interação entre indivíduos de sexos opostos.

Almeida et alii (1983) têm o mérito de apresentar um primeiro quadro das partículas do que eles chamaram de "Marcadores de sexo", o qual contém parte das partículas aqui discutidas, embora os autores não tratem do significado dessas partículas no discurso. Entretanto, os autores perceberam a distribuição dessas partículas segundo o sexo do falante em interação com o ouvinte (homem/ mulher). Reproduzimos, em seguida, a distribuição das partículas marcadoras de sexo do Apyãwa apresentada por Almeida et alii (p. 60):

"Assim, em fim de fala, surge amiúde uma forma que indica se é homem ou mulher que fala e se se dirige a homem ou mulher, afirmativa ou interrogativamente. Estas partículas não podem ocorrer depois de tãhê', em perguntas (cf. 23.4.2.1.).

Damos exemplos:

m-+m mamõ pa erea rãpy? kape ãa kã!

m-+h mamõ pã erea kihi? kape ãa kehê’!

h-+m mamõ pã erea ir? kape ãa ee!

li. -+h mamõ pã erea wã! kape ãa qi!

2.17 TABELA- Marcadores de sexo $\quad(\mathrm{h}:=\mathrm{h}$ omem;m $:=$ mulher $)$

\begin{tabular}{|l|l|l|}
\hline Fala & Afirmativa & Interrogativa \\
\hline m- $+\mathrm{m}$ & ka-! & rãpy? \\
\hline $\mathrm{m}-+\mathrm{h}$ & kehê'! & kihi? \\
\hline $\mathrm{h}-+\mathrm{m}$ & ee! & ii? \\
\hline $\mathrm{h}-+\mathrm{h}$ & qĩ & wã \\
\hline
\end{tabular}

Nas seções seguintes, apresentamos as partículas tal qual nos foram ensinadas pelos dois sábios Apyãwa.

\subsection{A distinção de gênero em expressões de parentesco}


Apresentamos, nos quadros seguintes, distinções entre a fala da mulher e da fala do homem encontradas nas expressões de parentesco, nos verbos para defecar e urinar e nas formas da interjeição, traduzidas aqui como 'ui', e que expressa surpresa,

\section{Termos de parentesco}

\begin{tabular}{|c|c|c|}
\hline GLOSSA & FALA DO HOMEM & FALA DA MULHER \\
\hline Sogro & $\begin{array}{l}\text { Xe ratyowa 'pai da } \\
\text { minha esposa' }\end{array}$ & Xe menowa 'pai do meu esposo' \\
\hline Sogra & $\begin{array}{l}\text { Xe raxa 'mãe da } \\
\text { minha esposa' }\end{array}$ & Xe meny 'a mãe do meu esposo' \\
\hline Filho & Xe ra'yra 'meu filho' & Xe memyra akoma'e 'meu filho' \\
\hline Filha & $\begin{array}{l}\text { Xe raxyra 'minha } \\
\text { filha' }\end{array}$ & Xe memy koxy (minha filha) \\
\hline $\begin{array}{l}\text { Filha mais } \\
\text { nova }\end{array}$ & $\begin{array}{l}\text { Xe raxyra pyrera } \\
\text { 'minha filha mais } \\
\text { nova' }\end{array}$ & $\begin{array}{l}\text { Xe memyra apyrera 'minha filha mais } \\
\text { nova' }\end{array}$ \\
\hline $\begin{array}{l}\text { Filha mais } \\
\text { velha }\end{array}$ & $\begin{array}{l}\text { Xe raxyry pykwera } \\
\text { ' minha filha mais } \\
\text { velha' }\end{array}$ & $\begin{array}{l}\text { Xe memyrypykwera 'minha filha mais } \\
\text { velha' }\end{array}$ \\
\hline Genro & $\begin{array}{l}\text { Xe raxywena 'meu } \\
\text { marido da minha } \\
\text { filha' }\end{array}$ & Xe peoma 'meu marido da minha filha' \\
\hline Nora & $\begin{array}{l}\text { Xe ra'ytaty 'esposa } \\
\text { do meu filho' }\end{array}$ & Xe memytaty 'esposa de meu filho' \\
\hline Neto/Neta & $\begin{array}{l}\text { Xe rymymino 'meus } \\
\text { netos/netas' }\end{array}$ & Xe remiarirõ meus netos/netas' \\
\hline $\begin{array}{l}\text { Filho/filha } \\
\text { do irmão }\end{array}$ & & Xe pega 'filho do meu irmão' \\
\hline $\begin{array}{l}\text { Filho } \quad \text { do } \\
\text { irmão mais } \\
\text { novo }\end{array}$ & $\begin{array}{l}\text { Xe rywyra ra'yra } \\
\text { pyrera }\end{array}$ & Xe pegapyrera \\
\hline $\begin{array}{lr}\text { Filho } & \text { do } \\
\text { irmão } & \text { mais } \\
\text { velho } & \\
\end{array}$ & $\begin{array}{l}\text { Xe ryke'yra ra'yry } \\
\text { pykwera }\end{array}$ & \\
\hline $\begin{array}{l}\text { Filha } \quad \text { do } \\
\text { irmão mais } \\
\text { novo }\end{array}$ & $\begin{array}{ll}\text { Xe rywyra } & \text { raxyra } \\
\text { pyera } & \end{array}$ & Xe kypy'yra memyrapyrera \\
\hline
\end{tabular}




\begin{tabular}{|c|c|c|}
\hline $\begin{array}{ll}\text { Filha } & \text { da } \\
\text { irmã mais } \\
\text { velha }\end{array}$ & $\begin{array}{l}\text { Xe renyra memyry } \\
\text { pykwera }\end{array}$ & Xe kypy'yra memyrypykwera \\
\hline irmã & $\begin{array}{l}\text { Xe renyra 'minha } \\
\text { irmã' }\end{array}$ & Xe kypy'yra 'minha irmã' \\
\hline $\begin{array}{ll}\text { Irmã mais } \\
\text { velha }\end{array}$ & $\begin{array}{l}\text { Xe renyry pykwera } \\
\text { 'minha irmã mais } \\
\text { velha' }\end{array}$ & $\begin{array}{l}\text { Xe kypy'yry pykwera 'minha irmã mais } \\
\text { velha' }\end{array}$ \\
\hline $\begin{array}{ll}\text { Irmã } & \text { mais } \\
\text { nova } & \end{array}$ & $\begin{array}{l}\text { Xe renyra pyrera } \\
\text { 'minha irmã 'mais } \\
\text { nova' }\end{array}$ & $\begin{array}{l}\text { Xe kypy'yra pyrera 'minha irmã 'mais } \\
\text { nova' }\end{array}$ \\
\hline Irmão & $\begin{array}{l}\text { Xe rywyra 'meu } \\
\text { irmão' }\end{array}$ & Xe kywyra 'meu irmão' \\
\hline $\begin{array}{l}\text { Irmão mais } \\
\text { velho }\end{array}$ & $\begin{array}{l}\text { Xe ryke'yry pykwera } \\
\text { meu irmão mais } \\
\text { velho }\end{array}$ & $\begin{array}{l}\text { Xe kywyry pykwer 'meu irmão mais } \\
\text { velho' }\end{array}$ \\
\hline $\begin{array}{l}\text { Irmão mais } \\
\text { novo }\end{array}$ & $\begin{array}{l}\text { Xe ryke'yra pyrera } \\
\text { 'meu irmão mais } \\
\text { novo' }\end{array}$ & $\begin{array}{l}\text { Xe kywyra pyrera 'meu irmão mais } \\
\text { novo' }\end{array}$ \\
\hline marido & & Xe mena 'meu marido' \\
\hline esposa & $\begin{array}{l}\text { Xe raty 'minha } \\
\text { esposa' }\end{array}$ & \\
\hline $\begin{array}{l}\text { Marido da } \\
\text { irmã }\end{array}$ & $\begin{array}{l}\text { Xe rajyra'yra } \\
\text { 'marido de minha } \\
\text { irmã', 'cunhado' }\end{array}$ & \\
\hline $\begin{array}{|ll|}\begin{array}{l}\text { Irmão } \\
\text { pai }\end{array} & \text { do } \\
\end{array}$ & $\begin{array}{l}\text { Xe rowyra 'irmão do } \\
\text { meu pai' }\end{array}$ & \\
\hline Irmã do pai & $\begin{array}{l}\text { Xe xaxe 'irmã de meu } \\
\text { pai' }\end{array}$ & \\
\hline $\begin{array}{|ll|}\begin{array}{l}\text { Irmão } \\
\text { pai }\end{array} & \text { do } \\
\end{array}$ & $\begin{array}{l}\text { Xe totyra 'irmão de } \\
\text { meu pai' }\end{array}$ & Xe totyri 'irmão de meu pai' \\
\hline \begin{tabular}{|lr} 
Irmã mais \\
velha de \\
meu pai
\end{tabular} & $\begin{array}{l}\text { Xe xaxey pykwera } \\
\text { 'irmã mais velha de } \\
\text { meu pai' }\end{array}$ & \\
\hline $\begin{array}{l}\text { Marido da } \\
\text { irmã mais } \\
\text { velha do pai }\end{array}$ & $\begin{array}{l}\text { Xe y'ywena 'marido } \\
\text { da irmã mais velha } \\
\text { de minha mãe' }\end{array}$ & \\
\hline
\end{tabular}




\begin{tabular}{|l|l|l|}
\hline $\begin{array}{l}\text { Esposa do } \\
\text { irmão da } \\
\text { minha mãe }\end{array}$ & $\begin{array}{l}\text { Xe totyraty 'esposa } \\
\text { do irmão da minha } \\
\text { mãe' }\end{array}$ \\
\hline $\begin{array}{l}\text { Irmã mais } \\
\text { velha da } \\
\text { mãe }\end{array}$ & $\begin{array}{l}\text { Xe y'yra 'irmã mais } \\
\text { velha de minha mãe' }\end{array}$ & \\
\hline $\begin{array}{l}\text { Marido da } \\
\text { irmã mais } \\
\text { velha da } \\
\text { mãe }\end{array}$ & $\begin{array}{l}\text { Xe y'ywena 'marido } \\
\text { da irmã mais velha } \\
\text { de minha mãe' }\end{array}$ & \\
\hline $\begin{array}{l}\text { Irmã do } \\
\text { marido }\end{array}$ & & Xe oke'i 'irmã do meu marido' \\
\hline $\begin{array}{l}\text { Irmã do } \\
\text { marido }\end{array}$ & Xe kywyra raty 'irmã do meu marido' \\
\hline $\begin{array}{l}\text { Marido da } \\
\text { irmã }\end{array}$ & $\begin{array}{l}\text { Xe kypy'yra mena 'marido de minha } \\
\text { irmã' }\end{array}$ \\
\hline $\begin{array}{l}\text { Marido da } \\
\text { irmã mais } \\
\text { velha }\end{array}$ & $\begin{array}{l}\text { Xe kypy'yry pykwera mena 'marido de } \\
\text { minha irmã mais velha' }\end{array}$ \\
\hline $\begin{array}{l}\text { Avô do } \\
\text { marido }\end{array}$ & & Xe menywyra 'avô do meu marido' \\
\hline $\begin{array}{l}\text { Avó do } \\
\text { marido }\end{array}$ & & Xe mexaryja 'avó de meu marido' \\
\hline $\begin{array}{l}\text { Vo c a ti vo } \\
\text { para mãe }\end{array}$ & Apĩ'irmão!' & \\
\hline $\begin{array}{l}\text { Vo c a ti vo } \\
\text { para irmã }\end{array}$ & Koxa 'irmã!' & \\
\hline
\end{tabular}

Esse quadro não é completo, mas serve para dar uma ideia da diferença da fala da mulher e do homem no âmbito desse campo semântico. A pesquisa continua de forma a oferecer um inventário mais completo da distinção em pauta.

\subsection{Distinções entre a fala feminina e masculina por meio dos verbos defecar e urinar}

Se a distinção da fala masculina e feminina no âmbito de termos de parentesco é uma característica comum às línguas Tupi-guarani conservadoras, há no Apyãwa inovações como Xe kywyrapyrera 'meu irmão mais novo', que atesta a diferenciação entre irmão mais novo e irmão mais velho da mulher, não atestada em outras línguas. O Apyãwa se diferencia de outras línguas da mesma 
família por apresentar formas supletivas dos verbos para 'defecar' e 'urinar', distribuídas segundo o sexo do falante. Essa distinção não foi ainda mencionada nos estudos sobre a língua apyãwa, nem reportada para outra língua dessa família linguística.

\begin{tabular}{|l|l|l|}
\hline Glossa & FALA DO HOMEM & FALA DA MULHER \\
\hline Urinar & Akorok'eu urino' & Ãkorok 'eu urino' \\
\hline Defecar & Apexakat 'eu defeco' & Apaxi 'eu defeco' \\
\hline
\end{tabular}

Distinção entre a fala feminina e masculina por meio da interjeição que expressa surpresa do falante com respeito ao conteúdo informacional de seu enunciado

\begin{tabular}{|l|l|l|}
\hline $\mathrm{Ui}$ & Ari & $A^{\prime} i$ \\
\hline
\end{tabular}

Eunice Dias de Paula, em sua tese de doutorado (2012, p.63), Eventos de fala entre os Apyãwa (Tapirapé) na perspectiva da etnossintaxe: singularidades em textos orais e escritos, ressalta a preocupação, anteriormente exposta por Mareaparygi Tapirapé (2006), com a substituição pelas mulheres da forma $a$ ' $i$ pela forma ari:

Outra mudança percebida pela autora é o desuso das marcas próprias da fala feminina como a'i, uma interjeição que exprime susto, ou a percepção de que a pessoa se enganou involuntariamente. As mulheres hoje estão usando para a mesma finalidade a partícula ari, que é própria da fala masculina. Assim, uma marca identificativa dos diferentes gêneros está sendo observada somente na fala de mulheres bem idosas (mais de 70 anos). Nossa hipótese para este caso é que isso se deve a proeminência que os homens adquiriram nas relações de contato com a sociedade não indígena. $\mathrm{O}$ papel tradicional de guerreiros, de protetores das mulheres e dos filhos, ampliou-se para uma nova função, a de serem os interlocutores com os não indígenas

A fala do homem e da mulher Apyãwa também se distingue por meio das partículas que ocorrem em final de enunciados convidativos e exortativos, nas seguintes situações:

\begin{tabular}{|l|l|l|}
\hline & Fala de um homem para outro homem & $K w \tilde{\imath} / k w \tilde{\imath}$, wã apexakat \\
\hline & Fala de uma mulher para outra mulher & $r a p y, k \tilde{a}$ \\
\hline & Fala de um homem para uma mulher & $h e, h i$ \\
\hline & Fala de uma mulher para um homem & $k e^{\prime} e, k{ }^{\prime} i$ \\
\hline
\end{tabular}


Observamos que a partícula kwĩ é usada nas interações entre homens, quando um homem convida, pede, ou chama outro homem para fazer algo juntos, ou quando, de alguma forma, o falante se vê envolvido no que enuncia. O uso dessa partícula é fundamental nas interações entre homens, assim como a partícula $w \tilde{a}$, descrita em seguida, por reiterarem as alianças existentes entre falante e ouvinte:

Exarapy kwĩ 'Vem cá, rapaz!'

Ere xaã kwĩ 'Vamos embora, rapaz!'

Epikapy kwĩ 'Espera aí, rapaz!'

Ere xika'anopy, kwĩ! 'Vamos roçar a mata, rapaz!'

Ere xaã ataararamõ, kwĩ! 'Vamos caçar, rapaz!'

Axexãopa ere kw̃̃! 'É verdade o que você está falando rapaz'

Ere xaã imota akamaxywa, kwĩ! 'Vamos trazer taquari, rapaz!'

Ere xika 'anopy, kwĩ! 'Vamos roçar a roça, rapaz!'

Ere, kwĩ! 'Vamos, rapaz!'

Ere xietyk xereka xerexewe, $k w \tilde{u}$ ! 'Vamos derrubar nossa roça para nós, rapaz!'

Xinogiũ ma'ema'e xerexewe, kwĩ, akerawet! 'Vamos plantar muita comida para nós, cunhado!'

Ere xaã ataararamõ, kwĩ! 'Vamos caçar, rapaz!'

Ere xaa xerepinapajta yryetepe, kwĩ ! 'Vamos pescar no rio, rapaz!'

Erexiapa kwĩ! 'Vamos fazer, rapaz!'

Ere xaã imota akamaxywamõ, kwĩ! 'Vamos buscar taquari, rapaz!'

Ximot temiära mõ xixekakiũ, $k w \tilde{l} !$ 'Vamos caçar um animal para nós alimentar, rapaz!'

Ereximaxa'ak kwĩ 'Vamos dividir, rapaz!'

A partícula wã em perguntas, como observado por Almeida et alii (1983): Ane pa wã? 'Você, rapaz?'

Ma'e pã wã, akerawet? 'O que foi, cunhado?'

Ere! Maryn pa wã? 'Vamos rapaz!'

Ta xe rairõ ere pã wã! 'Não é difícil, rapaz!'

Naxirekaj pã akaj ty'ãra ra'ẽ, wã! 'Ontem nós passamos fome, rapaz!'

Ari! Axetã kaj xirekaiũ ty'ãra ra'ẽ, wã! 'É verdade que ontem nós passamos fome rapaz!'

Eraryn, wã! 'mesmo, rapaz? 
Homens Apyãwa em interação - Fonte: Kamajrao (2015)

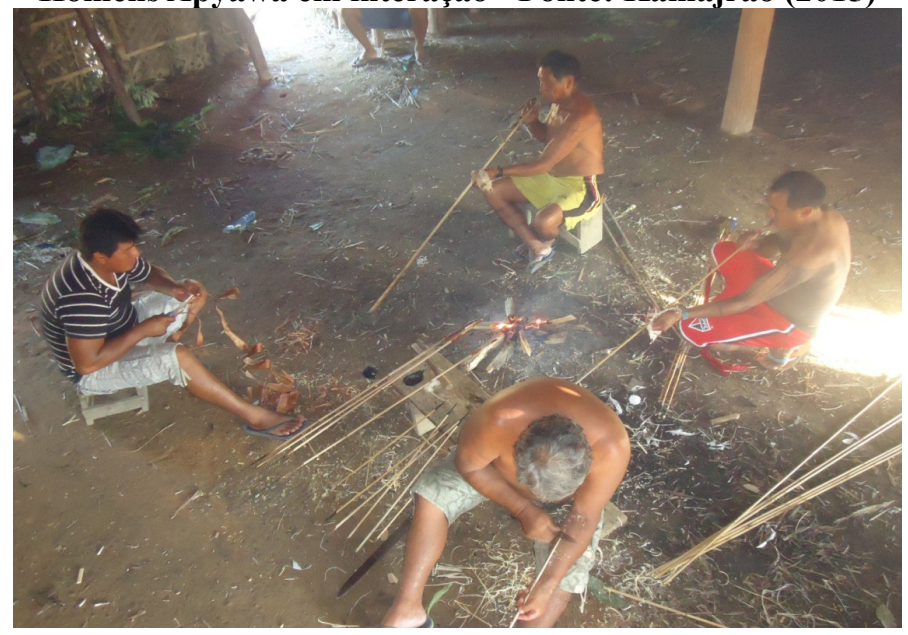

As mulheres, por sua vez, fazem uso das partículas rapy e $k \tilde{a}$, quando falam com outra mulher. Os dados coletados indicam que o uso da partícula rapy não se limita a enunciados interrogativos, como descrito por Almeida e Irmãzinhas de Jesus. É possível que o enfraquecimento do uso das marcas de gênero biológico na fala das mulheres tenha afetado a distribuição dessa partícula:

Exarapy 'ãwo! 'Vem cá!'

Araryn rapy! 'Sim, sou senhora!'

A'i! Ane pa rapy? 'Ui! É a senhora que está aí?'

Ane pa rapy? 'Você que está aí?'

Eraryn rapy! Ie 'ã aka 'Sim, estou aqui'

A partícula kã ocorre em comandos e exortações:

kwĩ Erõt kã ! 'Traga!'

Ere xikaro, $k \tilde{a} !$ 'Vamos comer!'

Ere xixaok kã! 'Vamos banhar!'

Ere xixemimõj, kã! 'Vamos cozinhar!'

Ere xixaok, kã! 'Vamos banhar!'

Ere xiket, kã! 'Vamos dormir!'

Ere xikapina xõ, $k \tilde{a}$ 'Vamos capinar o capim!'

Ere xipyej tyro, $k \tilde{a}$ 'Vamos lavar roupa!'

Ere xipyej xa'ẽ, $k \tilde{a}$ 'Vamos lavar panela!'

Xekypy'yrypykwera kã 'Minha irmã mais velha' 
Constata-se, também, o uso dessa partícula em enunciados apresentativos: Xekywyrapyrera, $k \tilde{a}$ 'É meu irmão mais novo' Xekypy'yrapyrera, $k \tilde{a}$ 'É minha irmã mais nova'

Fotos ilustrativas de mulheres interagindo no dia-a-dia - Fonte: Kamaira’i

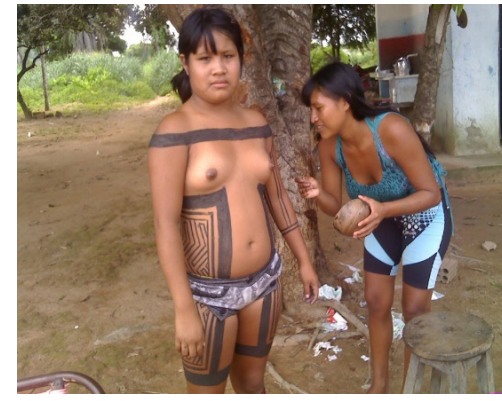

Iparexagato e Piri'i

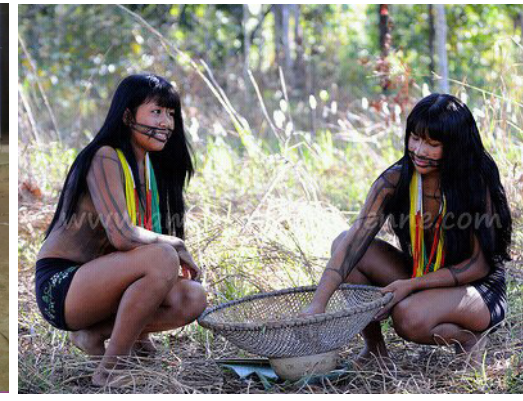

Mareaxigi e Marepoko

Outras partículas distintivas de gênero biológico são he/hi e ki'i /ke'e A fala do homem para mulher: Ane pa hi 'é você?'

A fala da mulher para homem: Exarapy he 'é você!'

Finalmente, há as partículas usadas pela mulher ao falar a um homem: Ane pa ki'i 'é você?'

Erot ke'e 'É você'

\section{O que dizem os Apyãwa sobre a distinção da fala do homem/fala de mulher}

Para sabermos mais sobre a importância e uso da fala masculina e da fala feminina, realizamos entrevistas com os sábios Korirã Jorge Tapirapé (70 anos de idade) e Taparawoo Tapirapé (68 anos de idade), moradores da aldeia Towajaatãwa.

Perguntados sobre a importância da distinção em pauta, Korirã Jorge Tapirapé observou que a distinção é antiga e “...importantíssima para o nosso povo se comunicar com eles e com elas. Faz parte da nossa verdadeira cultura e identidade étnica", que há muito tempo se originou para nosso povo". Para Taparawoo Tapirapé, as falas dos homens e mulheres Apyãwa são complexas e cada uma delas "...tem significado, pois cada sexo tem que cuidar do uso das falas, porque elas têm uma regra certa, não permitindo outra regra, tanto as falas das mulheres, quanto as falas dos homens.". Para Taparawoo, 
“...a nossa fala serve para comunicar e para especificar cada sexo Apyãwa. Também a fala é uma identificação do nosso povo Apyãwa, com a qual em qualquer reunião fora da nossa aldeia podemos ser identificados através das nossas falas originais. Mantendo a nossa identidade étnica, o povo Apyãwa nunca se esquecerá da sua própria verdadeira cultura e que a futura geração pode continuar valorizando a nossa cultura, como: crença, rituais, organização social...é importante a valorização das duas falas para que futuramente a nossa identidade étnica continue sendo viva e forte para a nova geração Apyãwa"

\section{Algumas palavras finais}

A pesquisa sobre as diferenças entre a fala feminina e masculina ainda deve ser aprofundada. Há ainda que se pesquisar em contextos naturais de fala entre os mais velhos outras expressões distintivas da fala feminina e masculina, inclusive, distinções prosódicas, como entonação e nasalidade, por exemplo. Os dados aqui apresentados apenas dão uma ideia de como a fala da mulher se diferencia da fala do homem. Não exploramos aqui as partículas $h i$ e he, nem as partículas kili e ke'e usadas pelas mulheres. Entretanto, os dados aqui abordados mostram a distinção valorizada tradicionalmente pelos Apyãwa e que é, sem dúvida, de grande importância para a identidade do povo.

\section{Referências}

Almeida, A. et alii. 1983. A língua Tapirapé. Rio de Janeiro: Xerox do Brasil (Série Reprográfica Xerox.

de Paula, Eunice Dias. 2012. Eventos de fala entre os Apyãwa (Tapirapé) na perspectiva da etnossintaxe: singularidades em textos orais e escritos. Tese de Doutorado, Faculdade de Letras, Universidade Federal de Goiás.

Tapirapé, Mareaparygi Lisete. 2009. O uso da língua Tapirapé. Monografia de conclusão do curso do Projeto Aranowa'yao, Ensino Médio, apresentada à Escola Indígena Estadual Tapi'itãwa, Aldeia Tapi'itãwa, Confresa, MT.

Rodrigues, Aryon Dall'Igna. 1984-1985. Relações internas na família linguística Tupiguarani. Revista Brasileira de Antropologia, vols. 27/28:33-53. 


\title{
O estatuto dos sintagmas posposicionais em Tene- tehára
}

\section{(Tupí-Guaraní)}

\author{
The status of the postpositional phrases in Tenetehára \\ (Tupí-Guaraní)' \\ Ricardo Campos Castro ${ }^{2}$
}

DOI 10.26512/rbla.v11i02.28454

Recebido em dezembro/2019 e aceito em dezembro/2019

\begin{abstract}
Resumo
O objetivo deste artigo é oferecer um tratamento teórico acerca da morfologia relacional de contiguidade que emerge no interior dos PPs em Tenetehára (Tupí-Guaraní). Evidenciarei o pressuposto teórico (cf. Kayne 1994) de que há apenas uma ordem básica dos constituintes nas línguas naturais, a saber: SVO. Assim, as outras ordens são alcançadas por meio de movimento. A partir desta premissa, as preposições seguem a ordem básica - núcleocomplemento - e as posposições são o resultado de uma ordem derivada. Ademais, demonstrarei o mecanismo de checagem de traços formais de Chomsky (1995). Finalmente, apresentarei minha hipótese sobre o modo como opera o mecanismo de checagem de traços que resulta em movimentos sintáticos e acionamento da morfologia relacional de contiguidade no interior dos PPs em Tenetehára. Em suma, defendo que a flexão relacional emerge como corolário da relação Spec-Head estabelecida em um sintagma acima do PP provisoriamente denominado KP.
\end{abstract}

Palavras-chave: Tupí-Guaraní, Tenetehára, Adposições, Concordância, Checagem de Traços.

\begin{abstract}
The aim of this paper is to provide a theoretical treatment of the relational contiguity morphology that emerges within the PPs in Tenetehára (Tupí-Guaraní). I will highlight the theoretical assumption (cf. Kayne 1994) that there is only one basic order of constituents in natural languages, namely: SVO. Thus, the other orders are achieved by moving. From this premise, prepositions follow the basic order - head-complement - and the postpositions are the result of a derived order. In addition, I will demonstrate Chomsky's (1995) formal feature checking mechanism. Finally, I will present my hypothesis about how the feature-
\end{abstract}


checking mechanism operates that results in syntactic movements and triggering of the relational contiguity morphology within the Tenetehára PPs. In short, I argue that relational flexion emerges as a corollary of the Spec-Head relation established in a phrase above PP provisionally called KP.

Keywords: Tupí-Guaraní, Tenetehára, Adpositions, Agreement, Feature Checking.

\section{Introdução}

Na língua Tenetehára, diferentemente do que ocorre em línguas românicas, emerge na adposição uma morfologia relacional cuja função gramatical será investigada neste artigo. Em termos descritivos, de acordo com Duarte (2007), os prefixos $\{\varnothing-\sim r-\}$ indicam a contiguidade do complemento em relação ao seu predicador, enquanto os prefixos $\{i-\sim h-\}$ indicam a não contiguidade desse complemento. Adicionalmente, observa-se o seguinte padrão: (i) as posposições que se iniciam com consoante recebem os prefixos $\{\varnothing-\sim i$ - $\}$ e (ii) as posposições que começam com vogal engatilham os prefixos $\{r-\sim h-\}$.

É importante destacar que a expressão "prefixos relacionais" advém do termo "prefixo de relação", proposto inicialmente por Rodrigues (1953, p. 124), o qual já havia capturado a função relacional que determinados núcleos estabelecem com seus complementos em Tupinambá. Cito ainda, Cabral (2001) e Rodrigues (2011) como importantes referências acerca do assunto. A fim de fornecer uma visão sinóptica desses afixos, apresento, a partir de Castro (2017), Camargos (2017) e Duarte (2007), o Quadro 1.

Quadro 1: Prefixos Relacionais

\begin{tabular}{c|c|c}
\hline $\begin{array}{c}\text { Contiguidade } \\
\text { ao complemento }\end{array}$ & $\begin{array}{l}\text { Raiz iniciada em } \\
\text { consoante }\end{array}$ & $\begin{array}{l}\text { Raiz iniciada em } \\
\text { vogal }\end{array}$ \\
\hline$\checkmark$ & $\varnothing-$ & $r-$ \\
$*$ & $i-$ & $h-$ \\
\hline
\end{tabular}

Nos exemplos ${ }^{3}$ (1) e (2), os padrões descritos no Quadro 1 podem ser observados. Note que, em (1), a posposição upi "em" - que se inicia por vogal - recebe os morfemas $\{r-\} e\{h$ - $\}$, os quais se distribuem em função da contiguidade ou não contiguidade em relação a seu complemento, de forma respectiva. Contudo, nos dados em (2), os prefixos $\{\varnothing-\}$ e $\{i-\}$ coocorrem com a adposição pupe "dentro" - iniciada por consoante - exibindo os ambientes de contiguidade e não contiguidade, nesta ordem.

3 Glosas: 1: primeira pessoa; 2: segunda pessoa; 3: terceira pessoa; c: prefixo que marca contiguidade do complemento; DIST: distal; DU: número dual (dual number); FF: forma fonética; LF: forma lógica (logical form); ITER: iterativo; NC: prefixo que marca não contiguidade do complemento; PL: plural; POss: possessivo; SBJ: sujeito (subject); SG: singular. 

(1a) ere-(e)xak
2sG-ver
kwaharer
$k a^{\prime} a$
r-upi ne
"Você vê o menino na mata"
mata C-em 2sG
(1b) ere-(e)xak
kwaharer
h-upi ne
2sG-ver
menino
$\mathrm{NC}-\mathrm{em} 2 \mathrm{SG}$
"Você vê o menino nela (na mata)"
(2a) u-zapo awa kyhaw tàpuz ø-pupe a'e
3-fazer homem rede casa c-dentro 3sG
"O homem faz rede dentro de casa"
(2b) u-zapo awa kyhaw i-pupe a'e 3-fazer homem rede NC-dentro 3SG "O homem faz rede dentro dela (da casa)"

A seguir, forneço em (3) e (4) exemplos com mais dois tipos de posposições. Contudo, o padrão de variação morfológica posposicional se mantém, conforme os exemplos (1) e (2), o que corrobora as assunções do Quadro 1.
(3a)
$\begin{array}{llll}\text { u-zar awa ita } & \text { r-ehe } & \text { a'e } \\ \text { 3-encostar homem pedra } & \text { C-em } & \text { 3sG } \\ \text { "O homem encosta na pedra" } & & \end{array}$
(3b) u-zar awa h-ehe a'e
3 -encostar homem NC-em 3sG
"O homem encosta nela (na pedra)"
(4a) u-hem Hikar taw o-pe a'e 3-chegar Ricardoaldeia C-em 3SG
"O Hikar chega na aldeia"
(4b) u-hem Hikar i-pe a'e
3-chegar Ricardo NC-em 3sG
"O Hikar chega nela (na aldeia)"

Nos exemplos em (3a), a posposição iniciada por vogal ehe "em" recebe o morfema $\{r-\}$ codificando adjacência do DP ita "pedra"; contudo, em (3b), emerge o morfema $\{h$ - $\}$, uma vez que não existe contiguidade do seu complemento. Ademais, nos dados em (4), são acionados os prefixos $\{\varnothing-\} e\{i-\}$ prefixadas à posposição $p e$ "em", codificando contiguidade e não contiguidade, respectivamente.

Este artigo está organizado em quatro seções. Na primeira seção, apresento esta introdução. Na segunda seção, descrevo, de acordo com Kayne (1994), o pressuposto teórico de que há apenas uma ordem básica dos constituintes nas línguas naturais, a saber: SVO. Assim, as outras ordens são alcançadas por 
meio de movimento de constituintes. A partir desta premissa, as preposições seguem a ordem básica, núcleo-complemento, e as posposições são o resultado de uma ordem derivada com o movimento do seu complemento para uma posição acima do núcleo. Na terceira seção, apresento, de forma sucinta, como ocorre o mecanismo de checagem de traços formais de acordo com Chomsky $(1995,1999,2000,2001,2005)$. Adicionalmente, teço considerações acerca da flexão relacional que emerge como subproduto da relação sintática estabelecida entre o núcleo $\mathrm{K}^{\circ}$ e o complemento movido para a posição Spec-KP. Além disso, apresento minha hipótese sobre o modo como opera o mecanismo de checagem de traços que resulta em movimentos sintáticos e o acionamento da morfologia relacional de contiguidade no interior de sintagmas posposicionais em Tenetehára ${ }^{4}$. Por fim, na quarta seção, desenvolvo as considerações finais deste artigo. Início, então, com as premissas de Kayne (1994) a respeito da ordem básica de constituintes.

\section{Ordem de constituintes e concordância}

Para Kayne (1994), há apenas uma ordem básica dos constituintes, a saber: [especificador [núcleo complemento]]. Esta ordem supõe a existência de uma assimetria, na qual o especificador e o complemento estão em lados opostos.

Trata-se do Axioma da Correspondência Linear (Linear Correspondence Axiom), doravante LCA. Segundo essa premissa, a ordem linear de uma sequência de itens lexicais em LF é definida pelo c-comando assimétrico. Esta assimetria fica constatada na configuração abaixo, tendo em vista que elementos à esquerda $(\alpha)$ estão em posição assimétrica em relação aos termos com os quais se concatenam $(\gamma 1$ e $\gamma 2)$. Mais especificamente, $\alpha$ c-comanda $\gamma 1$ e $\gamma 2$ mas $\gamma 1$ e $\gamma 2$ não c-comandam $\alpha^{5}$. Assim, o núcleo seleciona diretamente seu complemento, que é projetado à sua direita, enquanto seleciona indiretamente seu especificador, o qual é instanciado à esquerda, conforme pode ser visto na estrutura sintagmática abstrata a seguir:

(5)

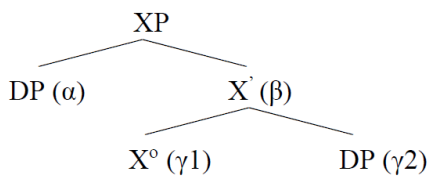

Nesta linha de investigação, o LCA prevê que todas as línguas dispõem da mesma ordem básica SVO, e que ordens diferentes dessa são o corolário do

4 Neste artigo, não examino como se realiza o acionamento da morfologia relacional de não contiguidade do complemento no interior de sintagmas posposicionais em Tenetehára. Em trabalhos futuros, analisarei a morfologia engatilhada nestes ambientes.

5 O comando simétrico é estabelecido entre $\alpha$ e $\beta$, já que estão numa relação de irmandade. Ou seja, estando no mesmo nível hierárquico, estes nódulos se c-comandam mutuamente. 
movimento de objetos sintáticos. Silva Filho (2018: 120) afirma que "quando essa ordem universal SVO não é aquela realizada em FF, o LCA mapeia os marcadores frasais de modo a determinar a ordem linear dos itens que aparecem em FF deslocados de sua posição de base".

Destarte, Kayne (1994) considera ainda ser pouco provável a existência de categorias sintagmáticas cujas ordens de base sejam diferentes de SVO. Nesta perspectiva, ele assevera que as ordens VSO, VOS, SOV, OVS e OSV são alcançadas porque as línguas permitem que seus constituintes possam ser deslocados, de modo a alterar a ordem básica. Desta maneira, "línguas (ou partes de línguas) em que algum complemento precede o núcleo associado devem necessariamente ter movido esse complemento para a esquerda do núcleo em alguma posição de especificador" " 6 (Kayne 1994:47).

Nesse sentido, PPs também seguem a ordem núcleo-complemento. Logo, em uma língua com preposições, ocorrem estruturas semelhantes à configuração (6) abaixo em que $\mathrm{P}^{\circ}$ é pronunciado antes de seu complemento.

(6)

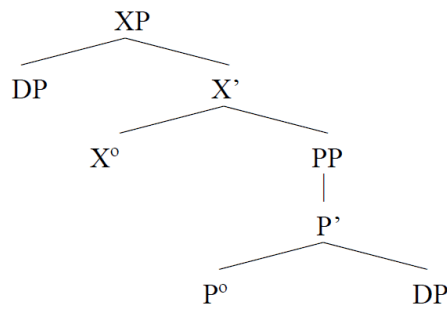

Contudo, em uma língua em que figurem posposições, a derivação deve se iniciar da mesma forma; mas, para alcançar a ordem com núcleo final é necessário o movimento do complemento para uma posição mais alta na estrutura sintagmática com o intuito de derivar a ordem especificador-núcleo. Nesse sentido, o autor afirma que "posposições devem ser derivadas movendose o complemento da adposição para a posição de especificador dessa adposição (ou de um núcleo funcional mais alto associada a ela) (Kayne 1994:47-48) ${ }^{7 ”}$.

Adicionalmente, conforme Kayne (1994), tanto em VPs quanto em PPs, é na relação Spec-Head que as concordâncias são estabelecidas. Por isso, é muito comum em línguas com adposições como núcleo final ocorrer concordância entre $\mathrm{P}^{\circ}$ e seu complemento. Isso gera uma regra na qual uma posposição só pode concordar com o seu complemento se este for movido para uma posição de especificador em um núcleo localizado acima do PP, o qual rotulo

6 "Languages (or subparts of languages) in which some complement precedes the associated head must necessarily have moved that complement leftward past the head into some specifier position" (Kayne 1994:47).

7 "postpositions must be derived by moving the complement of the adposition into the specifier position of that adposition (or of a higher functional head associated with it)" (Kayne 1994:47-48). 
provisoriamente de KP, conforme a seguinte representação:

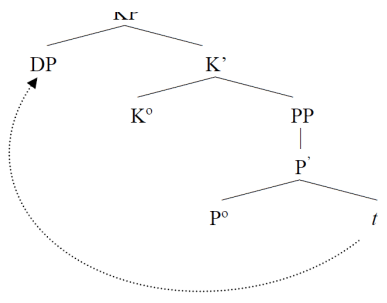

Kayne (1994) assevera que, na língua Navajo ${ }^{8}$, há concordância obrigatória entre as posposições e o seu complemento. O autor não apresenta exemplos, contudo, de fato, os dados a seguir, retirados de Young e Morgan (1980) e Mithun (2017), corroboram esta afirmação.

$\begin{array}{lll}\text { shighan } & \boldsymbol{b i} \text {-ch 'ị } & \text { yshááł } \\ \text { minha.casa } & \text { ela-em.direção.a } & \text { eu.andando }\end{array}$

Eu estou andando em direção à minha casa" (Young e Morgan 1980, p. 81)
yaateet
bi-káá ná-da-'iiid-l-wosh
pele.de.carneiro ele-em repetidamente-DIST-algo-1DU-SBJ-dormir.ITER

"Nós dormimos em pele de carneiro" (Mithun 2017, p. 47)

Note, nos exemplos em (8) e (9), os predicados verbais intransitivos, ysháá "eu (estou) andando" e náda iidlwosh "nós dormimos", e os PPs, shighan bich 'ị" "em direção à minha casa" e yaateeł bikáá "em pele de carneiro", respectivamente. Observe que o morfema $b i$ "ela/ele" ocorre no núcleo dos sintagmas posposicionais e concorda com seus complementos shighan "minha casa", em (8), e yaateel "pele de carneiro", no exemplo em (9).

Outra língua que também exibe a concordância entre a posposição e o DP que ela seleciona é o húngaro, conforme revelam os seguintes dados de Hornstein, Nunes e Grohmann (2005:124).

(10a) én-mögött-em

eu-atrás-POSs.1SG

"Atrás de mim"

(10b) te-mögött-ed

tu-atrás-POSs.2SG

"Atrás de você"

(10c) mi-mögött-ünk

nós-atrás-POSS.1PL

"Atrás de nós"

8 Língua indígena americana falada nos Estados Unidos e México. 
(10d) ti-mögött-etek

vocês-atrás-POSS.2PL

"Atrás de vocês"

(Hornstein, Nunes e Grohmann 2005:124)

Como se pode observar nos dados em (10), existe uma morfologia visível que reflete a concordância entre a posposição mögött "atrás" e o DP que ela seleciona. Considerando estas assunções iniciais e levando-se em conta o mecanismo padrão de Agree (cf. Chomsky 1995, 2000, 2001, 2005), tenho como objetivo propor como ocorre a derivação que resulta na ordem linear [especificador-núcleo], em que o núcleo do PP figura em posição de núcleo final. Na próxima seção, o objetivo é investigar como atua a checagem de traços conforme fora estabelecido por Chomsky (1995).

\section{Checagem de Traços - Chomsky (1995)}

De acordo com a teoria de Agree (cf. Chomsky 1995, 2000, 2001, 2005), a operação de movimento tem a função de checar traços, motivando o deslocamento de constituintes a partir de uma posição de base para uma posição derivada. Destarte, verbos se movem para posições de núcleos, ao passo que DPs se deslocam para posições de especificadores de categorias funcionais. A diferença entre as línguas se deve ao fato de que esses movimentos podem ocorrer antes ou depois do spell-out. Este termo, de acordo com Kenedy (2013:130), referese a uma bifurcação no curso da derivação sintática, uma espécie de fronteira divisória entre as divisões da forma fonológica e a LF.

A partir do Programa Minimalista (CHOMSKY 1995), o acionamento de parâmetros ao longo do processo de aquisição é concebido em termos de seleção de traços advindos do léxico. Tais traços podem ser de duas naturezas distintas, a saber: os interpretáveis (semânticos) e o não interpretáveis (formais). Os últimos apresentam funcionalidade tanto na derivação sintática quanto no nível de interface com o componente fonológico; contudo, eles não operam em LF, na interface com o componente semântico. Uma vez que o sistema computacional que opera sobre os traços os reconhece como objetos não interpretáveis nesta interface, ele os apaga em um ponto anterior à derivação atingir a LF.

Ademais, para que o sistema da língua seja considerado ótimo, faz-se necessário que operações como Move e Agree sejam motivadas, visando atender a condições de legibilidade do sistema sensório-motor. Assim, a motivação para Agree é formalizada da seguinte maneira: uma relação de concordância é estabelecida entre $\alpha$ e $\beta$. O primeiro possui traços formais não interpretáveis, os quais devem ser apagados/valorados; e o segundo porta traços formais interpretáveis valorados. Mais especificamente, um traço não interpretável e não valorado $[u \mathrm{~F}:[]$ atua como uma sonda (probe) buscando um alvo (goal), que possui um traço interpretável valorado [iF: val ]. Um alvo que porte um 
traço adicional não interpretável pode apagar/valorar este traço por meio de seu deslocamento para uma posição no domínio mínimo da sonda. Conectado a isso, o alvo precisa ser dotado de um traço de Caso estrutural (não interpretável, conforme $u \mathrm{X}$ abaixo) que o torne ativo (Activity Condition - Condição de Atividade) para participar da relação sonda-alvo e possíveis movimentos ulteriores, conforme as seguintes configurações ${ }^{9}$ abstratas:

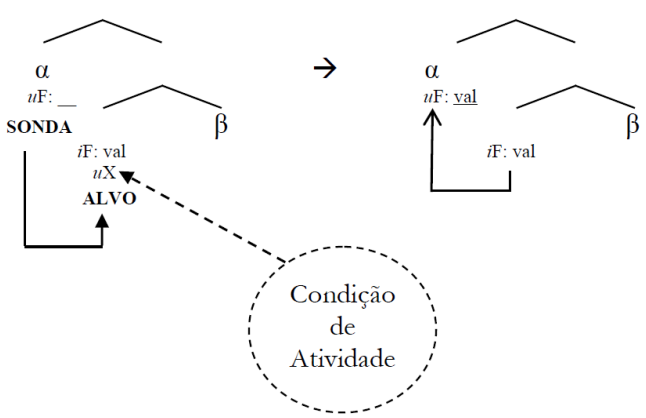

Adicionalmente, o EPP (Extended Projection Principle) e o Caso estrutural atuam de forma conjunta. Assim, o EPP determina a projeção da posição de especificador que irá abrigar o elemento movido e a existência do traço de Caso estrutural (não interpretável) torna esse elemento ativo para a relação sondaalvo e movimentos subsequentes, como já dito.

Chomsky (1999 e trabalhos posteriores) afirma que relações de concordância podem ser estabelecidas sem necessidade de movimento. Os traços não interpretáveis de número, pessoa e gênero (chamados traços- $\varphi$ ) e os traços de Caso estrutural (tais como o nominativo) podem ser valorados/apagados in situ. Nesse sentido, torna-se desnecessário o movimento do alvo (goal) para a posição de especificador de uma sonda (probe).

Nesta linha de investigação, o princípio denominado Procrastinar (Procrastinate, cf. Chomsky 1995) implica que um constituinte só se desloca se houver uma motivação. Mais especificamente, esta é uma regra de economia que prediz que movimentos de constituintes devem ocorrer o mais tarde possível, de preferência depois de Spell-out (i.e. na sintaxe encoberta). Contudo, de acordo com o autor, "a força de um traço é um dos elementos da variação linguística: um traço formal pode ser forte ou não, obrigando no primeiro caso ao movimento visível, em violação de Procrastinar"10 (Chomsky 1995:232).

9 Legenda dos símbolos utilizados na configuração em (12) bem como no restante deste artigo. $i \mathrm{~F}$ :val (traço interpretável e lexicalmente valorado); $u \mathrm{~F}$ : (traço não interpretável e não valorado); $u \mathrm{~F}: \underline{v a l}$ (traço não interpretável e valorado na sintaxe); $u \mathrm{~F}$ : val (traço não interpretável, valorado na sintaxe e deletado (Princípio da Interpretação Plena, Chomsky 1995)).

10 "feature strength is one element of language variation: a formal feature may or may not 
No modelo gerativo mais recente, apenas o EPP tem a capacidade de forçar um movimento, obrigando a projeção de uma posição de especificador necessária, a qual irá ser o local de pouso para que um elemento possa checar seus traços não interpretáveis.

Detalhando ainda mais a operação sintática Agree, nos termos de Chomsky (1995, 2000, 2001, 2005), a relação Spec-Head é considerada uma relação entre uma sonda e um alvo, Downward Agree (Concordância para Baixo). Essa concordância ocorre junto com um movimento engatilhado por um traço [EPP] independente no núcleo da sonda, a qual, carregando algum traço não interpretável e não valorado, procura em seu domínio de c-comando por um alvo que carrega um traço formal combinante interpretável e valorado. O traço combinante é uma exigência para que sonda e alvo possam ser legíveis para uma potencial relação de Agree. Ademais, reitera-se que o alvo mais baixo deve ser equipado com um traço não interpretável adicional, a Condição de Atividade, que irá ser checado/valorado com o núcleo mais alto como um efeito colateral de Downward Agree. O traço interpretável e valorado no alvo checa o traço não interpretável na sonda para valorá-lo. A checagem de traços é uma condição necessária para a deleção de traços formais não interpretáveis, uma vez que estes devem ser deletados no nível de LF. Cada traço não interpretável deve ser checado e valorado por meio da operação Agree no curso da derivação. Destarte, a versão padrão de Agree é definida em (12) e implementada de forma ilustrativa em (13).

Agree

(12) $\alpha$ pode estabelecer uma relação de Agree $\operatorname{com} \beta$ se e somente se $\alpha$ carrega pelo menos um traço não valorado e não interpretável e $\beta$ carrega um traço interpretável combinante valorado; $\alpha$ c-comanda $\beta$;

$\beta$ é o alvo mais próximo para $\alpha$;

$\beta$ possui um traço adicional não valorado e não interpretável (Condição de Atividade).

(13)

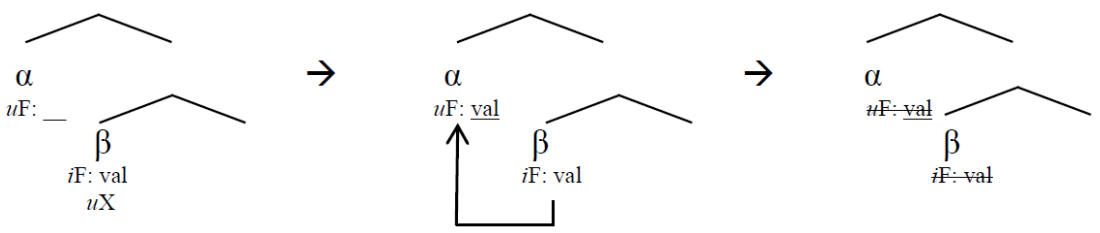

Na próxima subseção, apresento minha proposta de como submeter o quadro teórico delineado acima à lingua Tenetehára.

be strong, forcing over movement that violate Procrastinate" (Chomsky 1995:232). 


\section{Aplicações teóricas}

Tendo em conta a teoria sintática assumida acima, o intuito é explicar como se dão as operações sintáticas que geram a ordem com núcleo final no âmbito dos sintagmas posposicionais nos contextos de contiguidade em Tenetehára. Base Universal, c-comando assimétrico e Agree

Considerando a hipótese de base universal, o c-comando assimétrico e o mecanismo Agree, assumirei, doravante, que o acionamento da flexão relacional no interior dos sintagmas posposicionais na língua Tenetehára é reflexo da relação sintática de transmissão de Caso oblíquo que se estabelece entre o complemento e o núcleo do sintagma posposicional. Essa hipótese se fundamenta no fato de que a estrutura dos sintagmas posposicionais obedece ao mesmo princípio de checagem de traços formais que se dá no domínio funcional de outras categorias. Neste sentido, assumirei que, assim como o sujeito se eleva para a posição de especificador de TP a fim de receber Caso nominativo, os complementos das posposições também se deslocam para uma posição de especificador de uma categoria funcional acima de PP, com o intuito de checar o Caso oblíquo. Rotulo, provisoriamente, esta categoria funcional de $\mathrm{KP}$, conforme a estrutura arbórea delineada a seguir:

(14)

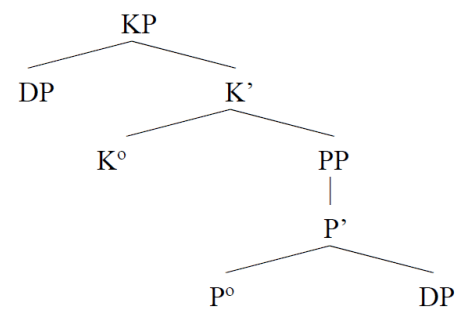

Note, em (15a) abaixo, que a estrutura dos PPs em Tenetehára apresenta a ordem [COMPL $\left.\left[\mathrm{X}^{\circ}\right]\right]$, diferentemente do que acontece com a ordenação sintática dos PPs em línguas românicas e germânicas, por exemplo, as quais apresentam a distribuição sintática [ $\mathrm{X}^{\circ}$ [COMPL]]. Estas diferentes ordenações são reflexo do fato de o núcleo $\mathrm{F}^{\circ}$ no domínio funcional do $\mathrm{PP}$, em Tenetehára, possuir um traço EPP, que obriga o movimento visível do complemento para posição de SpecFP antes de spell-out. Isto permite propor que a derivação da estrutura sintática do sintagma ita r-ehe "na pedra", em (15a), seja derivada como mostrado em (15b).

$\begin{array}{lllllll}\text { u-zar } & \text { awa } & {\left[_{\mathrm{Pp}}\right.} & \text { ita } & \text { r-ehe }] & & \text { a'e } \\ \text { 3-encostar } & \text { homem } & \text { pedra } & \text { C-em } & & \text { 3sG } & \\ \text { "O homem encosta na pedra" } & & & & \end{array}$


(15b)

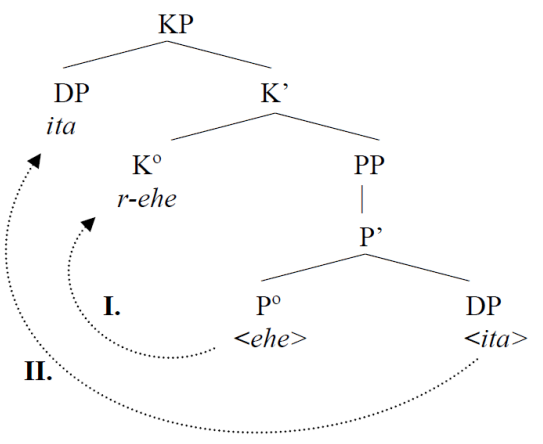

Em relação à ocorrência dos prefixos relacionais $\{r-\sim \varnothing-\}$ e $\{h-\sim i-\}$ nas posposições, Duarte $(2002,2007)$ assume que sua função pode ser interpretada como sendo consequência da atribuição de Caso abstrato operando entre um núcleo funcional e um DP que esteja em seu domínio de c-comando. Assim sendo, acompanhando o essencial da proposta de Duarte $(2002,2007)$, adotarei aqui a teoria segundo a qual a flexão relacional emerge como corolário da relação sintática estabelecida entre o núcleo $\mathrm{P}^{\circ}$ e o complemento movido para a posição de Spec-KP, numa relação Spec-Head. Em suma, a ocorrência desses prefixos pode ser vista como o reflexo, na sintaxe visível, do movimento do DP da posição sintática de complemento de PP para a posição de Spec- KP.

Tal situação não ocorre nas línguas românicas, uma vez que o núcleo de KP não aciona nenhuma flexão relacional nenhuma marca de concordância nas adposições. Assim, em português, o traço de Caso oblíquo é valorado/apagado à distância, conforme o princípio de economia Procrastinate, e o DP complemento de $\mathrm{P}^{\circ}$ permanece in situ nos sintagmas preposicionais, como mostra o exemplo (16a) abaixo e sua respectiva estrutura arbórea (16b):

(16a) O homem encosta $\left[_{\mathrm{PP}}\right.$ na pedra]

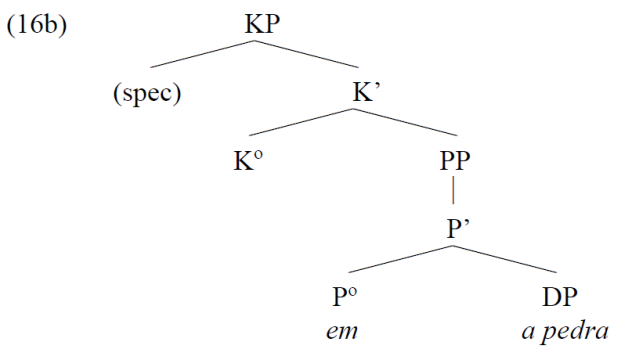

Em síntese, minha hipótese é a de que o engatilhamento da flexão relacional em Tenetehára sinaliza a valoração do Caso Oblíquo aos DPs complementos, que se movem para Spec-KP, o que não ocorre, por exemplo, em português. Nesta linha de investigação, assumo que em Tenetehára, o licenciamento do DP na estrutura do PP é vinculado à atribuição de Caso estrutural, situação em que 
Caso e concordância estão associados. Na próxima subseção, apresento minha hipótese de como opera o mecanismo de checagem de traços, resultando tanto em movimentos sintáticos quanto no acionamento da morfologia relacional de contiguidade no interior dos PPs na língua em análise.

\section{Acionamento da morfologia relacional de contiguidade}

Chomsky (1981) propõe o Princípio da Projeção (Projection Principle), estabelecendo que as propriedades de seleção de um núcleo lexical devem ser preservadas (realizados) em cada nível de representação gramatical, ou seja, DS, SS e LF (estrutura profunda, estrutura superficial e LF, respectivamente).

Porém, Chomsky (1982) agrega o Princípio de Projeção à especificidade de que as orações devem ter sujeito, renomeando o princípio como o EPP (Princípio de Projeção Estendido - Extended Projection Principle). Ademais, Chomsky (1995:232) afirma que "o Princípio de Projeção Estendido (EPP), plausivelmente, reduz-se a um traço D-forte de I" $"$.

Além disso, Chomsky (2000) atualiza ainda mais esta definição afirmando que o EPP é o requerimento de que certos núcleos funcionais devem ter especificador. Neste sentido, avento a hipótese de que em Tenetehára, o núcleo funcional $\mathrm{K}^{\circ}$ abriga um traço EPP, exigindo que o DP complemento de $\mathrm{P}^{\circ}$ se mova para a posição de especificador de $\mathrm{K}^{\circ}$ com o objetivo checar traços de Caso oblíquo.

A seguir, passo a descrever pormenorizadamente a derivação sintática de atribuição da morfologia de contiguidade aos PPs em Tenetehára. Observe que, em (17a), a posposição ehe se desloca de $\mathrm{P}^{\circ}$ para $\mathrm{K}^{\circ}$ com o objetivo de se completar morfologicamente. Note o feixe de traços no núcleo posposicional $\mathrm{P}^{\circ}$ $\left(=\mathrm{K}^{\circ}\right)$, a saber: $\left.([i \mathrm{C}: \mathrm{OBL}] ;[u \varphi:]]\right)$ e os respetivos traços combinantes $([u \mathrm{C}$ :

]; [i $i$ : 3sG]) no DP complemento de $\mathrm{P}^{\circ}$. Repare, ademais, que o requerimento "Condição de Atividade" é satisfeito pelo traço de Caso oblíquo não interpretável $[u \mathrm{C}]$ que o DP ita "pedra" carrega.

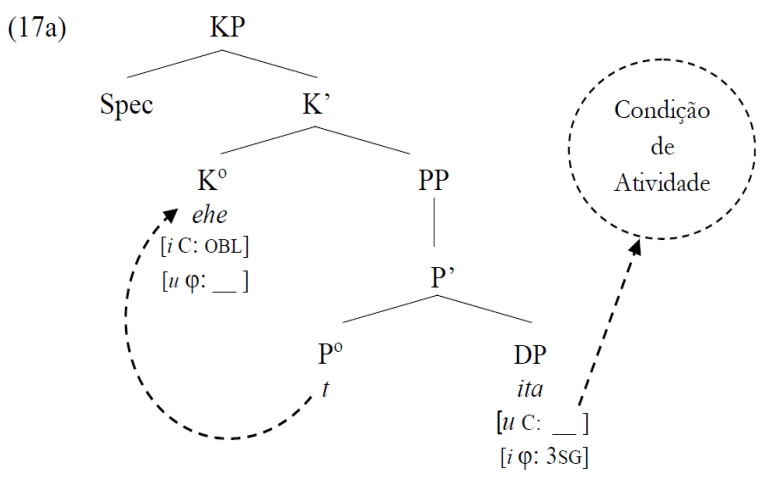

11 "the Extended Projection Principle (EPP) plausibly reduces to a strong D-feature of I." (Chomsky 1995:232). 
Perceba que, em (17b), a sonda Fo ehe "em" busca o alvo DP ita "pedra" de modo a poder valorar seus traços- $\varphi$ não interpretáveis e não valorados $[u \varphi$ : numa relação de c-comando. Assim, logo que a relação de agree é estabelecida, os traços $\varphi$ da sonda $\mathrm{K}^{\mathrm{o}}$ são valorados, conforme a seguir.

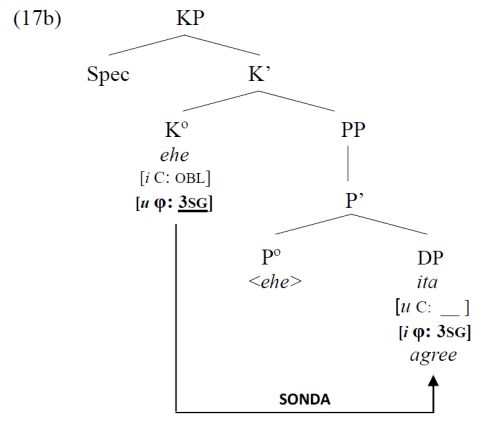

A derivação prossegue com o DP ita "pedra" se movendo para Spec- $\mathrm{F}^{\circ}$ a partir da posição de complemento do núcleo $\mathrm{P}^{\circ}$, a fim de checar seu traço de Caso oblíquo não interpretável $[u \mathrm{C}]$. Note que o traço EPP no núcleo $\mathrm{K}^{\circ}$ obriga que esta checagem seja via movimento e não à distância com este DP in situ. Nesse sentido, aqui, o Princípio Procrastinar não opera. Em Ko ${ }^{\circ}$ ocorrerá o Spellout da morfologia de atribuição de Caso abstrato nos termos de Duarte (2002, 2007). Mais precisamente, note que o prefixo $\{r-\}$ emerge como subproduto da relação sintática de valoração de Caso oblíquo estabelecida entre o núcleo $\mathrm{F}^{\circ}$ e o complemento de $\mathrm{P}^{\circ}$ movido para a posição de Spec-KP, em uma relação Spec-Head. Observe abaixo a configuração arbórea abstrata delineada em (17c), que permite visualizar, de forma mais clara, a checagem de traços (Agree) e o acionamento da morfologia relacional de contiguidade.

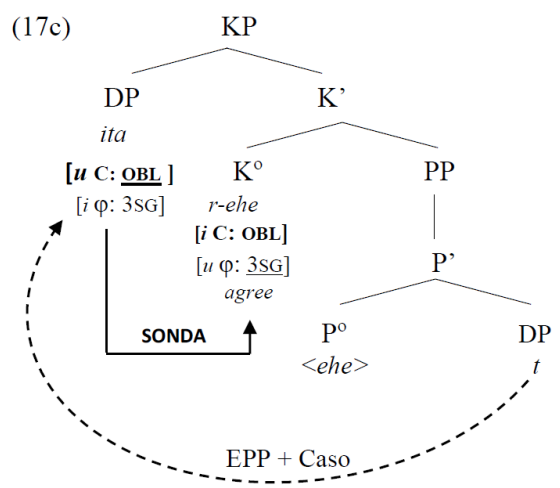

Note, a seguir, que, ao final da derivação em (17d), todos os traços não interpretáveis e não valorados são valorados e apagados, conforme estipula o 
Princípio da Interpretação Plena (Chomsky 1995:131).

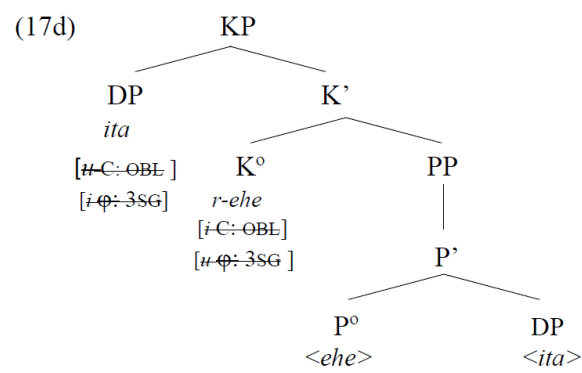

Após a proposta de aplicação do quadro teórico assumido neste artigo, apresento a seguir as considerações finais.

\section{Considerações Finais}

Neste artigo, investiguei teoricamente a morfologia relacional de contiguidade que emerge nas adposições em Tenetehára (Tupí-Guaraní). Conforme Duarte (2007), a morfologia relacional pode ser sistematizada da seguinte forma: (i) os prefixos $\{\varnothing-\sim r-\}$ indicam a contiguidade do complemento em relação ao seu predicador, enquanto os prefixos $\{i-\sim h-\}$ indicam a não contiguidade desse complemento; (ii) as posposições que se iniciam com consoante recebem os prefixos $\{\varnothing-\sim i-\}$ e as posposições que começam com vogal engatilham os prefixos $\{r-\sim h-\}$. Descrevi, de acordo com Kayne (1994), o pressuposto teórico de que há apenas uma ordem básica dos constituintes nas línguas naturais, a saber: SVO. Assim, as outras ordens são alcançadas por meio de movimento de constituintes. A partir desta premissa, as preposições seguem a ordem básica, núcleo-complemento, e as posposições são o resultado de uma ordem derivada com o movimento do seu complemento para uma posição acima do núcleo, no especificador de um sintagma o qual rotulei provisoriamente como KP. Ademais, apresentei como ocorre o mecanismo de checagem de traços formais de acordo com Chomsky (1995, 1999, 2000, 2001, 2005). Adicionalmente, teci considerações acerca da flexão relacional que emerge como subproduto da relação sintática estabelecida entre a posposição no núcleo $\mathrm{K}^{\circ}$ e o complemento movido para a posição Spec-KP. Finalmente, formulei minha hipótese sobre o modo como opera o mecanismo de checagem de traços que resulta em movimentos sintáticos e o acionamento da morfologia relacional de contiguidade no interior de sintagmas posposicionais em Tenetehára.

\section{Referências}

Cabral, Ana Sueli Arruda C. "Prefixos Relacionais na família Tupí-Guaraní". 2001. In: M.E. (org). Boletim da ABRALIN. Fortaleza: Imprensa Universitária/UFC, no25, p. 213-226. 
Camargos, Quesler F. 2017. Aplicativização, causativização e nominalização: uma análise unificada de estruturas argumentais em Tenetehára-Guajajára (Família Tupi-Guarani). Tese de Doutorado, Universidade Federal de Minas Gerais.

Camargos, Quesler F., e Ricardo C. Castro. 2013. "Paralelismo entre DP e CP a partir das nominalizações na língua Tenetehára." Revista da ANPOLL 34: 393-434.

Castro, Ricardo C. 2017. Morfossintaxe Tenetehára (Tupí-Guaraní). Tese de Doutorado, Universidade Federal de Minas Gerais.

Chomsky, Noam. 1981. Lectures on government and binding. Dordrecht: Foris.

Chomsky, Noam. 1982. Some concepts and consequences of the theory of government and binding. Cambridge: MIT Press.

Chomsky, Noam. 1995. The Minimalist Program. Cambridge, MIT Press.

Chomsky, Noam. 1999. Derivation by phase. Cambridge, MIT Press.

Chomsky, Noam. 2000. "Minimalist inquiries: The framework." In Step by step: Essays on minimalist syntax in honor of Howard Lasnik, editado por R. Martin, D. Michaels e J. Uriagereka, 89-115. Cambridge, MIT Press.

Chomsky, Noam. 2001. "Derivation by phase.” In Ken Hale: A life in language, editado por M. Kenstowicz, 1-52. Cambridge, MIT Press.

Chomsky, Noam. 2005. "Three factors in language design." Linguistic Inquiry 36 no. 1 (Winter): 1-22.

Duarte, Fábio B. 2002. "Negação e movimento do verbo na língua Tembé." In Atas do Encontro internacional do GT de Línguas Indígenas da ANPOLL, Belém, 2002, 374-384. Belém: Universidade Federal do Pará.

Duarte, Fábio B. 2007. Estudos de morfossintaxe em Tenetehára. Belo Horizonte: FALE/UFMG.

Hornstein, Norbert, Jairo Nunes, e Kleanthes K. Grohmann. 2005. Understanding minimalism: an Introduction to Minimalist Syntax. Cambridge: Cambridge University Press.

Kayne, Richard S. 1994. The antisymmetry of Syntax. Cambridge: The MIT Press.

Kenedy, Eduardo. 2013. Curso básico de linguística gerativa. Editora Contexto: São Paulo.

Mithun, Marianne. 2017. "Argument marking in the polysynthetic verb and its implications." In The Oxford Handbook of Polysynthesis, editado por Michael Fortescue, Marianne Mithun e Nicholas Evans, 30-58. Oxford: Oxford University Press.

Rodrigues, Aryon D. 1953. "Morfologia do Verbo Tupi”. Letras, Curitiba, n. 1, p. 121152.

Rodrigues, Aryon D. 2011. “Argumento e predicado em Tupinambá”. Revista Brasileira de Linguística Antropológica, v. 3, n. 1, p. 93-102.

Silva Filho. Jomson T. (2018). Linearização e hierarquia no sistema computacional da linguagem humana, retomando o paradoxo posicional a partir do programa 
minimalista. 143 f. Tese (Doutorado em Letras e Linguística: Linguística) Faculdade de Letras, Programa de Pós-Graduação em Letras e Linguística, Universidade Federal de Alagoas, Maceió.

Young, Robert W., e William Morgan. 1980. The Navajo Language: A Grammar and Colloquial Dictionary. Albuquerque: University of Mexico Press. 